\title{
Healthcare Professionals’ Adoption of Clinical IT in Hospital: A View of Relationship between Healthcare Professionals and Hospital
}

\author{
Pouyan Esmaeilzadeh*, Murali Sambasivan
}

Graduate School of Management, Universiti Putra Malaysia, Selangor, Malaysia

\begin{abstract}
The application of IT has become significant in the health sector. Clinical IT is considered as a strategic tool to improve efficiency of health care delivery and effectiveness of physicians in the health care sector. New technologies that change the traditional practice patterns of healthcare professionals in hospitals cannot be simply accepted by them. There is enough evidence to claim that healthcare professionals are not willing to accept and use clinical IT that interferes with their day-to-day work activities. If healthcare professionals do not use new clinical IT, all the effort, money and resources used for the implementation of the system have no result. However, factors affecting healthcare professionals' acceptance of clinical IT are still not fully identified. In this study, an extension to TAM is used to incorporate the unique characteristic of physicians, physicians' computer literacy and features of clinical IT. The extended model has been developed to chiefly address the issues of IT adoption amongst healthcare professionals in a hospital setting. A survey has been conducted to evaluate the model among 300 healthcare professionals in Malaysia. The structural equation model has been used to test the model in this context. The results reflect the role of perceived threat to professional autonomy, healthcare professional-hospital relationship, perceived usefulness and perceived ease of use in determining healthcare professionals' intention to use clin ical IT systems in Malaysia. The proposed model can explain 51\% of the variance of physicians' intention to accept clinical IT.
\end{abstract}

Keywords TAM, Perceived Threat to Professional Autonomy, Healthcare Professional-Hospital Relationship, Perceived Organizational Support, Affective Commitment, Clinical IT Systems

\section{Introduction}

The rapid development of Information Technology (IT) has made organizations to take advantage of using IT in increasing their competitiveness[1]. There is a wide range of applications of IT in different fields [2, 3, 4, 5]. IT is not only dominant in high tech industries but also in other sectors such as health sector[6]. According to Kluge[7], if hospitals cannot use the applications of IT to manage information exchange as well as enhance health care services, they will lose their patients' trust. Also, the utilizat ion of IT can lead to cost cutting and restructuring medical industry for the 21st century [8]. At present, clinical IT is being used in healthcare industry to support highly specialized tasks[11].

The main challenge for any new technology is the intention to adopt and use the technology. If the usage rate is low, the technology can no longer be effective for organizations [13,14]. According to Delone and McLean[15],

* Corresponding author:

pouyanes@yahoo.com (Pouyan Esmaeilzadeh)

Published online at http://journal.sapub.org/mm

Copyright (C) 2012 Scientific \& Academic Publishing. All Rights Reserved the important way to measure IT success is how much the system is accepted and used by users. However, based on the IT adoption behavior in health sector, healthcare professionals have not fully utilized the potential resource of clinical IT[6, 16, 17, 18, 19, 20, 21]. There is a growing concern within IT adoption research among healthcare professionals because of the problems in adoption and use of clinical IT.

Thus, user acceptance is the key indicator of the successful adoption of a newly introduced IT[23,24,25,26,27,28]. In the past, a variety of theoretical models attempted to facilitate explaining and predicting user acceptance of a new IT.[23,24,25,26,27,29]. Technology Acceptance Model (TAM) which is developed by Davis, is one of the most widely accepted IT adoption models[23,24]. TAM suggests that factors such as perceived usefulness and ease of use determine the intention to use a particular system. According to Hu et al[30], there is evidence that TAM cannot predict well IT adoption behavior amongst healthcare professionals. Based on Succi and Walter[31], the reason is traced back to the unique circumstances considered for medical decision making. Also $\mathrm{Hu}$ et al.[32] argue that the difference between healthcare professionals and other IT users is because of 
professional characteristics of healthcare professionals such as specialized training, professional autonomy and professio nal work settings. Therefore, the existing variables embedde $\mathrm{d}$ in TAM cannot fully explain healthcare professionals, motives to accept new clinical IT. There is a strong need to search for additional context-based motivational factors.

According to Tierney[33], the relationship between individuals and organizational entities can be a challenging and influential factor in the process of IT change. Results of the research done by Magni and Pennarola[34] support the key role of relational beliefs in the technology adoption process. Yet, very little literature has investigated technology acceptance from a relational viewpoint in a hospital setting. So, this is a sign of a significant gap in the field of healthcare professionals' IT adoption behavior.

As a result, this study attempts to provide an understanding on the role of healthcare professional-hospital relationship and unique characteristics of healthcare professionals in the acceptance and utilization of clinical IT. Also, this study addresses the gap seen in the IT adoption literature by combining TAM, professional autonomy and healthcare professional-hospital relationship to improve the success of clinical IT implementation in hospitals.

\section{Theoretical Background}

\subsection{Theories of IT Adoption}

With attention to the important role of users in the utilization of technology's potential value, the behavior of users in the introduction of a new IT is still under discussion. [35]. Based on Agarwal and Karahanna[36], the strategic value of investment in a new IT can be obtained as the new IT is accepted and utilized consistently by users in order to achieve organizational goals. When users accept to use new technology, they become more prone to change their long-standing work activities with the use of the new system [22].

Based on individual intention to accept new technology, eight theoretical models have been developed. According to the literature on theories of intention and IT adoption, the eight models are: Theory of Reasoned Action (TRA), Technology Acceptance Model (TAM), Motivational Model (MM), Theory of Planned Behavior (TPB), a combined theory of planned behavior/technology acceptance model (C-TAM-TPB), Model of PC utilization (MPCU), Innovation Diffusion Theory (IDT), and Social Cognitive Theory (SCT). Ven katesh et al.[37] co mbined all the existing models and put forward a unified model called Unified Theory of Acceptance and Use of Technology (UTAUT). All these models are designed to explain and predict the individual's willingness to employ new technologies[42].

Based on a body of literature, TAM is the most influential IT adoption model and is widely applied to explain the IT acceptance process in different contexts[38]. Davis derived TAM from TRA in 1989 to mainly explain technology use in various situations and cultures in order to increase user acceptance of systems. Another reas on for usefulness as well as popularity of TAM is traced back to its parsimony, simp lic ity, understandability and gaining empirical support within a variety of user groups [46].

The original TAM suggests that two beliefs namely, perceived usefulness and perceived ease of use play a pivotal role in underscoring individual acceptance of a new technology $[39,40]$.The first variable, perceived usefulness, is considered as the degree to which a person believes that by making use of a particular system his job performance would be enhanced[23]. The second one, perceived ease of use, is operationally defined as the extent to which a person believes that using a particular system would be effortless [23]. These factors can be addressed during the system development stage to solve the users' acceptance problem [41]. These factors determine behavioral intention that is found by a wide number of studies[48], as a better predictor of actual system usage. In the field of social science, intention to use a new IT is defined as user willingness to actual behavior of using the new IT.

\subsection{Weakness of TAM Within Healthcare Professionals}

Although TAM has been the focus of many studies and employed as a useful tool to explain the technology acceptance process, this model doesn't explain and predict the behavior of healthcare professionals[17]. According to $\mathrm{Hu}$ et al[30], TAM has received significant attention from a large number of information science researchers, but it is not applicable in the health professional context. This is due to the fact that determinants embedded in TAM are still very general and not designed for any particular profession[22]. Each profession has some distinctive contextual characterist ics that may in fluence users' IT adoption behavior.

Some studies have been conducted in the health sector to explain healthcare professional's IT adoption behavior. For instance, Schaper and Pervan[43] outline that healthcare professionals are not likely to use those types of technologies that change the nature of their established work routines. This idea is supported by Anderson[52] and Anderson \& Aydin[53]. According to these researches, the willingness of healthcare professionals decreases when they notice that new technology invalidates their continuous practice patterns. These new technologies are usually like a new challenge for the profession[44, 45]. Healthcare professionals are not completely aware of full potential and application of new IT and they haven't fully used the new systems [46]. According to Aggelidis and Chatzoglou[50], healthcare professionals seem to react differently toward the introduction of a new technology based on their priorities. Literature indicates that healthcare professionals are slow and very pragmatic in terms of accepting and using new technology[51]. Also, according to Horan et al.[47], healthcare professionals' acceptance of a new IT is a function of organizational readiness in the process of organizational change.

As a result, the existing variables embedded in TAM cannot completely determine healthcare professionals' motives to adopt new technology. Another extension to the 
TAM is needed to explore other determinants that could influence perceived ease of use, perceived usefulness and intention to use new clinical IT in the healthcare environment.

One of the most pivotal variables is healthcare profession als' unique characteristics that should be integrated with the TAM to gain a better understanding of professional IT adoption. Another issue that should be taken into consideration is the relationship between healthcare professional and the organization he/she serves (hospital) in order to study how relational beliefs regarding healthcare professionals and hospitals influence organizational readiness to accept new changes (such as the introduction of new clinical IT).

\subsection{Professional Autonomy: the Main Privilege}

According to Sharma[49], the holders of some occupations (such as medical practice) are defined as professionals. The healthcare professionals considered in this study consist of all kind of physicians from different medical specialty areas. This group can make use of clinical IT potentials to imp rove health care delivery and efficiency. Professionals have been attributed some unique and professional characteristics that make them different from other non-professionals. As stated by Brennan and Coles[54], healthcare professionals' professionalism is rooted in a set of values. The most important characteristic is healthcare professional autonomy and the other features are patient sovereignty, physician confidentiality, and habits of learning. According to Chau and $\mathrm{Hu}[11]$, the differences between healthcare professionals and other user groups in terms of accepting new IT derive from a set of values such as:

Specialized train ing which is obtained over a considerable period gives them the knowledge and expertise that is required in this profession[55]

Professional autonomy is defined as the control that professionals have over the processes, conditions and content of their medical practice[56]. Literature states that professional autonomy is the most important professional value provided for healthcare professionals [57].

The third characteristic is professional work arrangements where healthcare professionals are considered as health care providers, hospitals become health care facilities, and patient are both the product and the client in the healthcare environment [55, 58]. Beside professionals, there are two other occupational groups in a hospital. The para-profession al group, such as medical assistants, owns only partial professional knowledge and skill and assists healthcare professionals in their healthcare practices. The last group is non-professionals who are just prepared to engage in running clerical, office work and ad min istrative duties.

Due to professional autonomy, healthcare professionals have power over non-professionals and para-professionals and can control the tasks conducted by them[59]. So, healthcare professionals try to support the factors that strengthen their professional autonomy and defend against the factors that may erode their professional autonomy[22].
Despite the significant role of professional autonomy in healthcare professionals IT adoption behavior, less emphasis has been placed to explore whether and how this central characteristic influences healthcare professional'sacceptanc e of new clinical IT[22].

\subsection{Clinical IT in the Healthcare Industry}

In this section, two main types of clinical IT that is classified as a subgroup of HIT (Health Information Technology), have been discussed. These systems are Electronic medical report systems (EMR), and Clinical Decision Support systems (CDS). The application of each system is as follows:

(1). EMR systems are computer systems that allow patient charts to be created, kept, revised, and retrieved on a computer[22]. EMR positively affects efficiency with automated procedures, better documentation, and standardized clinical tools. Furthermore, EMR can lead to efficiency improvement by the use of reducing repeated treatments, saving time by compiling patient data and resources needed for medical record, storing patient charts, med ications and allergies[60].

(2). CDS systems are computer systems that regarded as an application of Decision Support System (DSS), which takes patient data as input and generates decision- specific advice[61, 62]. Moreover, these systems are referred to as knowledge-based systems that by the use of a set of reasoning techniques can suggest diagnostic options and care planning. Typically, clinical IT is designed to improve decision-making in health care environ ment[10, 22].

The issue of the threatening effects of clinical IT on healthcare professionals' professional autonomy is still in question in IT adoption studies. Literature states that instructions, rules, regulations and recommendations which are an integral part of clinical IT can change healthcare professionals' traditional work activities and may encroach on their professional autonomy[65]. The nature of instructions and treatment options suggested by clinical IT is oriented to guide healthcare professionals' behavior in clinical decision making. It means clinical IT can restrict medical practice and it seems that the systems advise healthcare professionals what to do for treatment of their patients. So, healthcare professionals perceive these systems as threatening to their professional autonomy and they become an xious and less likely to use them[51, 66].

\subsection{Social Relationship with the Organization}

Based on a literature review, healthcare professional's IT adoption behavior is not only affected by their special characteristics, but also their decision making regarding acceptance of new IT depends on organizational context[34, 11]. The individual relationship with organizational entities is rooted in social exchange theory[63]. According to the theory, social exchange concerns voluntary actions of individuals with the beliefs that favorable behavior would be repeated in the future. Literature indicates that relational beliefs affect emp loyee outcomes and also their satisfaction 
[64]. Past studies on relational beliefs argue about two factors affecting the employee-organization relationship: perceived organizational support and affective commitment $[67,68]$. According to Rhoades and Eisenberger[69], employees are likely to attribute human-like features to the organization. Establishment of favorable perceptions about the relationship with the organization is a function of advantageous effects exerted by the organizations[70]. Based on the amount of support they receive from the organization, they attribute a favorable or unfavorable feature to the relationship. Also employees can get an emotion-based relationship with the organization on the basis of their affective commit ment[68].

\subsection{Healthcare Professional- Hospital Relationship}

\subsubsection{Perceived Organizational Support}

This concept is on the basis of the extent to which the organization cares about employees' welfare[67]. Literature places emphasis on the role of perceived organizational support in employees' effort and outcome[71]. So, employees with a high level of perceived organizational support recognize that the amount of effort they made to perform their job effectively is observed by the organization. Also, employees with a high level of perceived organizational support become in line with the organizational goals and mission[67]. According to a review of literature, the positive effect of perceived organizational support becomes more significant in stressful situations [34]. As a consequence, perceived organizational support is negatively related to employees' level of stress[72]. Based on Eby et al.[73] and Self et al.[74], organizational support perceived by employees mitigates negative reaction toward an organizational change. According to Korunka et al.[75], introducing a new technology can increase the level of stress for employees who are faced with the challenge of accepting and using the system while maintaining high level of performance.

In the healthcare industry, healthcare professionals are very sensitive to changes made by a new IT in their traditional work activities[77]. Any new IT system is supposed to reduce dependence on specific personnel[78.79]. As indicated by some studies, the main reason that makes healthcare professionals reluctant to use new IT is traced back to a fear of making change in their traditional medical practices[52, 80, 81, 82]. So, Healthcare professionals should change their practice pattern and adopt the instructions, rules and recommendations of clinical IT (which are considered as threatening to their professional autonomy) in order to accept and use the new system. Therefore, the introduction of new clinical IT is a source of stress and perceived threat to professional autonomy[22]. Hence, if healthcare professionals perceive that the hospital supports them during the introduction of new clinical IT, they feel less threatened by the new system. Also they feel that they are aided by the hospital about coping with the rules and regulations of clinical IT and how to interact with the system. As a result, the ability of hospitals to provide healthcare professionals with proper tools and useful information exchange makes healthcare professionals perceive less threat and stress concerning the use of the new clinical IT.

\subsubsection{Affective Commitment}

The concept of commitment is generally defined as individuals' psychological state to retain as a member of an organization[76]. There are different kinds of behavioral consequences for commitment such as job performance[83] and organizational citizenship behaviors [84]. Besides, there are different types of commitment in the literature as follows:

a) Affective commitment: that is defined as having tendency to remain in the organization.

b) Continuance commitment: that is defined as perceived cost of leaving the organization.

c) Normative commitment: that is defined as perceived obligation to maintain membership in the organization.

Past studies draw attention to the relationship between affective commitment and cooperation as well as supporting behaviors[85, 86]. According to Magni and Pennarola[34], affective commitment makes employees more likely to work cooperatively with other members and also increase their effort to emb race an organizational change. So, employees who demonstrate a high level of affective commitment to the organization, become more active to support change initiatives[87]. So me researchers have mentioned the effect of commitment on the introduction of innovation[88]. According to Armenakis and Bedeian[87], organizational readiness for change is main ly affected by commit ment.

As discussed previously, organizational readiness affects healthcare professionals' acceptance of a new IT[47]. Also, because the introduction and implementation of clinical IT is regarded as a significant change in healthcare industry, affective commitment may play an important role in using the new organizational change. Like other individuals, healthcare professionals with a high level of affective commitment are more likely to make extra effort to change. So, with a high level of affective commitment, they perceive less threat by clinical IT because they tend to understand the purpose of the new system's rules and recommendation to improve health care delivery. As a conclusion, healthcare professionals who show a high level of affective commitment to the hospital feel less threatened by new clinical IT and may exert more effort to use the system.

The following section explains the conceptual framework developed for the study. The constructs and relationships mentioned in the study are also manifested by hypotheses development.

\section{Conceptual Framework: Technology Acceptance from a Relational Perspective}




\subsection{The Negative Effect of Perceived Threat to Professional Autonomy on Intention to Use Clinical IT}

Healthcare professionals' intention to use new clinical IT is the dependent variable which refers to individual willingness to accept a new technology[23]. The role of the main unique characteristic of healthcare professionals is manifested by perceived threat to professional autonomy. This construct is defined as "the degree to which a person believes that using a particular system would decrease his or her control over the conditions, processes, procedures, or content of his or her work'[22]. Therefore, the first hypothesis is developed as follows:

HI. Healthcare professionals' perceived threat to professional autonomy is negatively related to their intention to use new clinical IT in a hospital setting.

\subsection{Perceived Usefulness and Perceived Ease of Use}

Literature highlights the significant role of perceived usefulness and perceived ease of use as the two key predictors of individual intention to use a new IT[e.g., 89]. Perceived usefulness concerns the performance expectations that users have about using a new IT. Therefore, as long as healthcare professionals perceive clinical IT as a source of performance enhancement they become more willing to use the system. So, the next hypothesis is developed as follows:

H2. Healthcare professionals' perceived usefulness is positively related to their intention to use new clinical IT in a hospital setting.

In line with Davis[17], intention to use new IT systems is positively related to perceived ease of use. Chang et al.[5] have stated that effort expectancy is a significant predictor for physicians' intention to use CDS. As supported by Kijsanayotin et al.[9], effort expectancy is a key factor in shaping physicians intention to use technology. Therefore, if healthcare professionals find the new clinical IT easy to understand and use, they become more likely to use the system in their practice pattern. Thus, the next hypothesis states this idea as follows:

H3. There is a positive relationship between perceived ease of use and healthcare professionals' intention to use clinical IT in a hospital setting.

\subsection{Healthcare Professional-Hos pital Relationship Vs. Perceived Threat to Professional Autonomy}

The relationship between a healthcare professional and the hospital can be presented by two factors: perceived organizational support and affective commitment. As mentioned previously, these factors have a significant role in the process of IT change[33]. Organizational support directed by hospitals can reduce healthcare professionals' stress and perceived threat regarding the introduction of new clinical IT. In other words, being aided by hospitals can lead to decreased adverse reactions to organizational change. So, the next hypothesis is developed as follows:

H4. Perceived organizational support is negatively related to healthcare professionals' perceived threat of clinical IT to professional autonomy in a hospital setting.

Besides, organizational readiness plays an important role in healthcare professional IT adoption[47]. Based on previous studies, affective commitment contributes to organizational readiness for change. Therefore, with greater affective commitment, healthcare professionals become more aware of the process of IT change and become more willing to employ rules, procedures and recommendations given by clinical IT to improve the medical practice. Consequently, they feel less threatened by instructions of new clinical IT. Therefore, the following hypothes is is:

H5. Affective commitment is negatively related to healthcare professionals' perceived threat of clinical IT to professional autonomy in a hospital setting.

The following figure depicts the conceptual framework developed in this study:

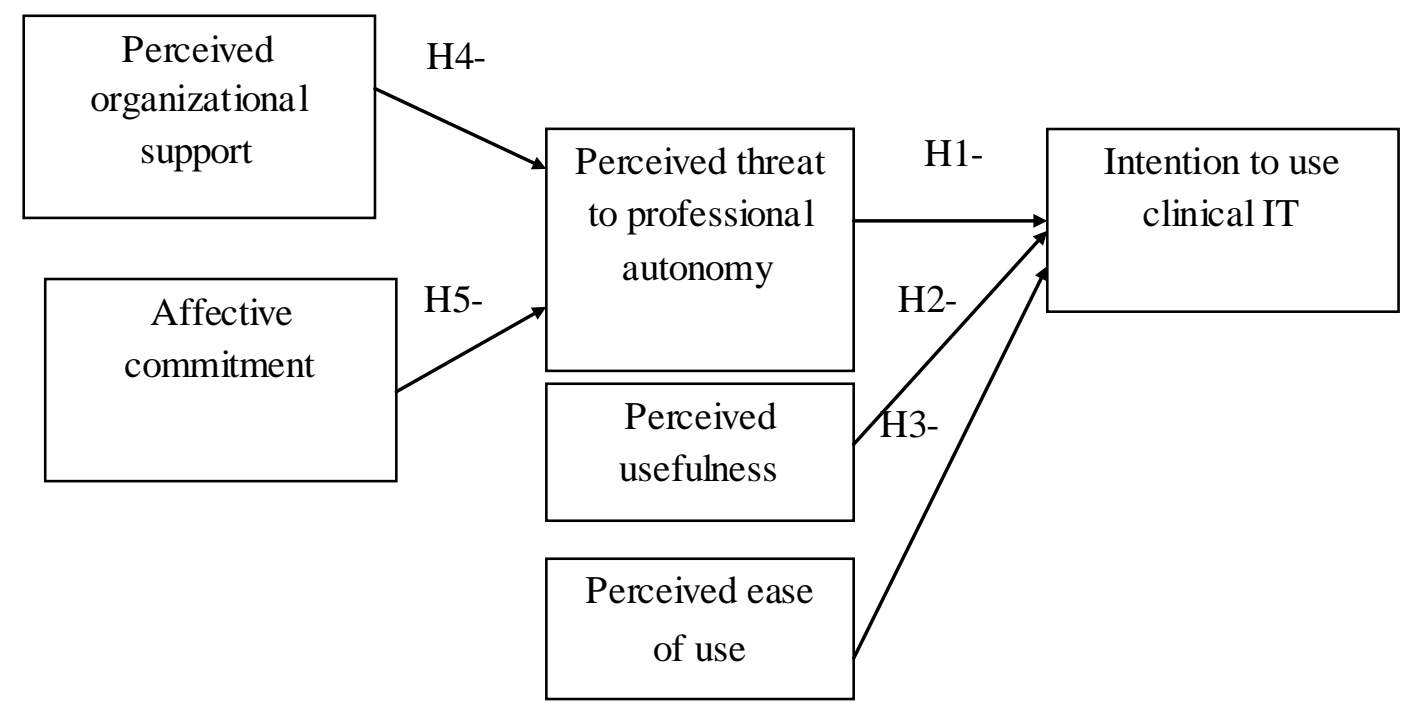

Figure 1. The healthcare professional-hospital relationship 


\section{Empirical Analysis}

\subsection{Data Collection}

The purpose of this study is to identify factors affecting healthcare professionals' clinical IT adoption. Data for this study were collected by the use of a questionnaire distributed among physicians with different specialties in 12 Malaysia's hospitals. In our analys is, 300 valid questionnaires were used. Roughly equalnumbers of men and wo men were represented. Respondents' major fields included General Practitioners (14.6\%), Surgeon (14.6\%), Pediatric (12.6\%), Gynecologist (11\%), Internist (10.7\%), Anesthesiologist (8.7 \%), Radiologist (7.1\%), Geriatric (6.8\%), and Psychiatrist (6.1\%). Approximately $80 \%$ of the physicians reported moderate to very high level of familiarity with clinical IT.

\subsection{Me asurement}

The questionnaire was used to measure the five constructs embedded in the research model. All measurement items were adapted from established sources and measured on a five-point Likert scale with anchors of strongly agree (5) and strongly disagree (1). The items used to measure perceived usefulness and perceived ease of use were adapted from Davis[17] and Davis et al.[19]. Intention to use was measured based on six items adapted from $\mathrm{Hu}$ et al.[30]. Perceived threat to professional autonomy was measured using six items adapted from Walter and Lopez[3]. Perceived organizational support was assessed through four items derived from Wayne et al.[58]. An exemplar item is "Help is availab le from the company when I have a problem with the system". Affective commitment was measured through four items adapted from Meyer et al.[59]. An exemplar item is "I do not feel a strong sense of belonging to my organization” (reverse item).

\subsection{Reliability and Construct Validity}

The survey items were tested for scale reliability. The Cronbach's alpha scores for the five constructs were greater than the acceptable level of 0.7 indicating high internal consistency. Construct reliability was assessed using evaluation of factor loading as well as examining the composite reliability and Average variance Extracted (A VE). All constructs exhibited co mposite reliability greater than the acceptable level of 0.7 indicating that the measurement errors were relatively small[60]. AVE value for all constructs was also greater than 0.5.To assess the discriminant validity between constructs, the test that requires the square root of $\mathrm{AVE}$ for each construct to be higher than the correlation between the two associated latent variables was performed. All factors meet the criteria for discriminant validity as shown in Table 1.

\subsection{Results}

The hypotheses of this study were tested by AMOS 16 . After confirming the measurement model, the structural model was then examined. Six common model-fit measures were employed to assess the model's overall goodness-of-fit: the ratio of $X^{2}$ to degrees-of-freedom(d.f.), the comparative fit index (CFI), the Tucker-Lewis Index (TLI), the normalized fit index (NFI), the root mean square residual (RMR), and the root mean square error of approximation (RMSEA). Commonly, model fit is obtained when $x 2 /$ d.f. is lower than 3, the CFI, GFI and NFI are higher than 0.90, RMR is lower than 0.05 and the RMSEA is lower than 0.08 [61]. in this study, The model fit indices are: $\mathrm{CFI}=0.91$, NFI $=0.90, \mathrm{TLI}=0.90, \mathrm{RMR}=0.057, \mathrm{RMSEA}=0.052, \mathrm{x}$ $2 /$ d.f. $=1.833$. These indices are within the prescribed limits and therefore, the model reflects a good fit to the data[62]. All the hypotheses were accepted at 0.01 .

The hypotheses were tested based on the structural model and the results are:

H1: There is a significant positive relationship between perceived usefulness and intention to use clinical IT $(\beta=$ 0.45 , p-value $<0.01$ ).

$\mathrm{H} 2$ : There is a significant positive relationship between perceived ease of use and intention to use clinical IT $(\beta=$ 0.27, p-value $<0.01$ ).

H3: There is a significant negative relationship between perceived threat to professional autonomy and intention to use clinical IT $(\beta=-0.36$, $p$-value $<0.01)$.

H4: There is a significant negative relationship between perceived organizational support and perceived threat to professional autonomy $(\beta=-0.53, \mathrm{p}$-value $<0.01)$.

H5: There is a significant negative relationship between affective commitment and perceived threat to professional autonomy $(\beta=-0.37$, $\mathrm{p}$-value $<0.01)$.

In summary, the two constructs, perceived organizational support and affective commitment jointly explain 54\% of perceived threat to professional autonomy. The model also indicates that perceived usefulness, perceived ease of use and perceived threat to professional autonomy jointly explain $51 \%$ of the variance in intention to use clinical IT among physicians in Malaysia.

Table 1. Cronbach's Alpha (CR), Composite reliability (COMP) andAVE of constructs (diagonal of the mat rix cont ains the square root of AVEs, off-diagonal elements are the correlation bet ween constructs)

\begin{tabular}{|c|c|c|c|c|c|c|c|c|c|}
\hline Constructs & CR & COMP & AVE & INT & PU & PEOU & PT & POS & AC \\
\hline INT & 0.82 & 0.81 & 0.64 & $\mathbf{0 . 7 7}$ & & & & & \\
\hline PU & 0.90 & 0.91 & 0.72 & 0.54 & $\mathbf{0 . 8 5}$ & & & & \\
\hline PEOU & 0.86 & 0.90 & 0.71 & 0.45 & 0.68 & $\mathbf{0 . 8 7}$ & & & \\
\hline PT & 0.87 & 0.90 & 0.69 & -0.46 & -0.17 & -0.18 & $\mathbf{0 . 8 3}$ & & \\
\hline POS & 0.81 & 0.82 & 0.58 & 0.52 & 0.59 & .51 & -0.47 & $\mathbf{0 . 7 3}$ & \\
\hline AC & 0.83 & 0.85 & 0.54 & .48 & 0.45 & .48 & -0.50 & 0.52 & $\mathbf{0 . 7 9}$ \\
\hline
\end{tabular}




\section{Discussion and Conclusions}

Recently, investment in IT in health care practices has increased. A variety of IT systems has gradually become established in the healthcare industry. Clinical IT in healthcare sector is considered as a key element in improving the quality of medical care. However, the concern of having underused clinical IT systems still is one of the biggest is sues for the clinical IT developers[6, 63]. This study tries to determine the motives that make physicians adopt clinical IT. The results show that physicians' decision to adopt clinical IT depends on the following factors: perceived threat to professional autonomy, perceived usefulness and perceived ease of use. This research explains that the degree to which a physician is threaten by clinical IT affects his/her intention to use the system. If physicians perceive treatment options and guidelines of clinical IT against their autonomous practice in Malaysia's hospitals, they feel threatened by clinical IT and in turn they become less likely to use the system.

In line with previous research, this study also reveals that perceived usefulness is an important factor for physicians to adopt clinical IT. The results stress the significant positive effect of instrumental benefits in intention of physicians to adopt clinical IT in a developing country like Malaysia. If physicians perceive that using clinical IT can improve their job performance in Malaysia's hospitals, they become more motivated to use the system in their practice patterns. In this study, obtaining more utility by using the system turns out to be the most important motives for physicians to adopt clinical IT in the context of Malaysia.

This study shows the significant effects of perceived ease of use on decision making to adopt clinical IT among physicians in Malaysia. Effort-oriented concept related to using clinical IT concerns with the belief that utilizing clinical IT is free of effort. If physicians find clinical IT easy to use they become more willing to apply the system in their day-to-day work activities in hospitals. This study signifies the importance of easy features of clinical IT to improve motivation of physicians in a developing country like Malaysia.

Healthcare professionals' behavior toward clinical IT has been considered as a critical challenge in the healthcare industry regarding utilization of the strategic value of the new technology. They put more emphasis on their professional autonomy and resist using clinical IT if they are threatening. In this study unique characteristics of healthcare professionals as well as relational beliefs are integrated with the TAM in order to solve healthcare professionals' difficulties using clinical IT. To improve the overall healthcare professionals' clinical IT acceptance, this study introduces healthcare professional- hospital relationship. Perceived organizational support and affective commitment are presented as the two dimensions of healthcare professionals' relationship with hospital. This study states that the ability of a hospital to support healthcare professionals makes healthcare professionals feel less threatened by clinical IT. In addition, a high level of healthcare professionals' affective commitment leads to low level of threat perceived by clinical IT and makes them exert extra effort to support organizational change by adopting new clinical IT in hospital.

What are the contributions of this study? Medical care practice is one of the oldest professions regarded as a relatively independent profession[12]. But Change is coming to healthcare sector and it can't be ignored. The utilization of IT in hospitals has three important outcomes: enhancing the quality of services delivered, improving the efficiency and effectiveness of the hospitals' personnel and cutting the organizational expenses[64]. An advanced clinical IT in a hospital without physician acceptance is like having a modern art museum without visitors. Adoption of physicians gives meaning to clinical IT in a hospital. From a theoretical point of view, this study contributes to IT adoption theories explaining physicians' intention to accept new technology. Since the TAM cannot address healthcare professionals' unique characteristics and it is not fit the healthcare context, this study has been conducted to better explain physicians' IT adoption behavior in a hospital setting. The research model developed by this study can explain 51\% of the variance in physicians' clinical IT adoption behavior.

Implementing and using clinical IT in a developing country like Malaysia can be a challenge for hospital administrators. From a practical view, this study suggests that the hospital mangers and decision makers must take following initiatives to improve adoption of clinical IT by physicians. As far as the negative effect of perceived threat is concerned, this study informs managers of hospitals in Malaysia about concerns and fears of threat perceived by physicians due to clinical IT. Hospital managers should give much attention to professional characteristics of healthcare professionals such as autonomous practice to foster their priorities in IT adoption. This study also suggests that the hospital managers should develop a good and profitable relationship between healthcare professionals and hospitals to achieve the full potential of new clinical IT. To do so, hospital management may focus on the development of a sound and change-oriented organizational environment in order to affect organizational readiness to gain greater IT acceptance. The study also recommends that hospital managers should emphasize the advantage and us efulness of using clinical IT to motivate physicians to use clinical IT. This research suggests that clinical IT must have easy features and include user friendly elements for the physicians to perceive that using the instructions given by the system is easy. With this understanding hospital management can improve overall acceptance of clinical IT by healthcare professionals in Malaysia's hospitals.

This study has some limitations. First, the study was conducted in private and public hospitals in Malaysia. The factors affecting the adoption of clinical IT in hospitals could be different in other developing countries. Second, our study included the hospitals in and around the capital city, Kuala 
Lumpur, and these hospitals are highly developed and superior compared to the facilities in the rural areas. Therefore, this study does not strongly recommend generalizing the results to the hospitals in the rural areas.

\section{REFERENCES}

[1] T. Dewet, G. R.Jones, “The role of information technology in the organization: a review, model, and assessment”. Journal of Management, Vol 27, no. 3, pp. 313-346,

[2] P.Guriting, O. N., Ndubisi, "Borneo online banking: Evaluating customer perceptions and behavioral intention". Management Research News, Vol. 29, no.1/2, pp.6-15, 2006.

[3] P.Ratnasingam, D. Gefen, P. A. Pavlou, “The role of facilitating conditions and institutional trust in electronic marketplaces”. Journal of Electronic Commerce, Vol. 48, no.3, pp. 69-82, 2005.

[4] S. Srinivasan, "Role of trust in e-business success". Information Management \& Computer Security, Vol. 12, no.1, pp. 66-72, 2004.

[5] M.Reid, Y.Levy, “Integrating Trust and Computer Self-Efficacy with TAM: An Empirical Assessment of Customers' Acceptance of Banking Information Systems (BIS) in Jamaica”. Journal of Internet Banking \& Commerce, Vol. 13, no. 3.

[6] F.C. Tung, S.C. Chang, C.M. Chou, “An extension of trust and TAM model with IDT in the adoption of the electronic logistics information system in HIS in the medical industry". Int. J. Med. Inform. Vol. 77, pp. 324-335, 2008.

[7] E.W.Kluge, “ Secure e-health: managing risks to patient health data”. Int.J.Med.Inform, Vol. .76, pp.402-406, 2007.

[8] J. Flower, "Digital technology essential and subversive”. The Physician Executive. Vol. 30, no. 2, pp. 42-45, 2004.

[9] M. Andrews, “The Hospital of the Future”. U.S. News \& World Report, 00415537, Vol. 146, no. 7, 2009.

[10] D.Pain, K., Fielden, R.A.Shibl, “Options on the use of clinical decision support systems for paediatric prescribing in a New Zealand hospital”, Logistics Information Management, Vol. 16, no. $3 / 4$, pp. 201-206, 2003.

[11] P.Y.K. Chau, P.J.Hu, "Examining a model of information technology acceptance by individual professionals: an exploratory study", Journal of Management Information Systems, Vol. 18, no. 4, pp.191-229, 2002.

[12] J. Holsinger, B., Beaton, "Physician professionalism for a new century”, Clinical Autonomy, Vol. 19, pp. 473-479, 2006.

[13] K. Mathieson, "Predicting user intentions: comparing the technology acceptance model with the theory of planned behavior”. Information Systems Research, Vol. 2, no.3, pp.173-191, 1991.

[14] J.Y. Chang, L.K. Chen, C.C. Chang, "Perspectives and expectations for telemedicine opportunities from families of nursing home residents and caregivers in nursing homes". International Journal of Medical Informatics, Vol. 78, no. 7, pp. 494-502, 2009.

[15] W. Delone \& E. McLean, “Information sy stems success: The quest for the dependent variable”. Information Systems Research, Vol. 3, no. 1, pp. 60-95, 1992.

[16] M.Y. Yi, J.D. Jackson, J.S. Park, J.C. Probst, “Understanding information technology acceptance by individual professionals: Toward an integrative view”, Information and Management, Vol. 43, pp.350-363,2006.

[17] W.G.,Chismar, S.Wiley-Patton, "Does the extended technology acceptance model apply to physicians". Proceedings of the 36th Hawaii International Conference on System Sciences, 2003.

[18] K. Dearne, “Health’s tech bypass, in The Australian”, Sy dney, pp. 1-4, 2003.

[19] D.,Murray, "Healthcare challenge, In Australian Information Week”, vol.3, pp.10-18, 2002.

[20] A. Wenn, A. Tantnall, C. Sellitto, P. Darbyshire, S. Burgess "A sociotechnical investigation of factors affecting IT adoption by rural GPs', in Information Technology in Regional Areas”, Using IT: Make IT happen, Online, Rockhampton, Queensland Australia, 2002.

[21] M.Western, K. Dwan, T.Makkai, C. del Mar, J.Western, "Measuring IT use in Australian General Practice", University of Queensland, Australia, 2001.

[22] Z., Walter, M.S. Lopez. "Physicians acceptance of information technology: Role of perceived threat to professional autonomy”, Decision Support Systems, Vol.64, pp.206-215, 2008.

[23] F.D. Davis, "Perceived usefulness, perceived ease of use, and user acceptance of information technology”. MIS Quarterly, Vol. 13, no. 3, pp. 319-340, 1989.

[24] F.D.Davis, "User acceptance of information technology: system characteristics, user perceptions and behavioral impacts". International Journal of Man-Machine Studies, Vol.38, no. 3, pp. 475-487, 1993.

[25] F.D. Davis, R.P. Bagozzi, P.R. Warshaw, "User acceptance of computer technology: A comparison of two theoretical models”. Management Science, Vol. 35,no.8, pp. 982-1003, 1989.

[26] J.E. Kottemann, F.D. Davis, "Decisional conflict and user acceptance of multicriteria decision making aids". Decision Science, Vol. 22, no. 4, pp. 918-926,1991.

[27] M. Igbaria, "User acceptance of microcomputer technology: an empirical test”, Omega, Vol. 21, no. 1, pp.73-90, 1993.

[28] M., Igbaria, , T.Guimaraes, G. Davis, “Testing the determinants of microcomputer usage via a structural equation model”. Journal of Management Information Systems, Vol. 11, no. 4, pp.87-114, 1995.

[29] S.M. Lee, Y.R. Kim, J.Lee, “An empirical study of the relationships among end-user information systems acceptance, training, and effectiveness". Journal of Management Information Systems, Vol. 12, no. 2, pp. 189-202, 1995.

[30] P.J. Hu, P.Y.K. Chau, O.R. Sheng, K.Y.Tam, “Examining the technology acceptance model using physician acceptance of 
telemedicine technology”. Journal of Management Information Systems, Vol. 16, no. 2, pp.91-112,1999.

[31] M.J.Succi and Z.D.Walter, “ Theory of user acceptance of information technologies: an examination of healthcare professionals”. Presented at the $32^{\text {nd }}$ Hawaii international conference on system sciences, Hawaii, USA, 1999.

[32] D. Gefen, D.W.Straub, M. Boudreau, "Structural equation modeling and regression: Guidelines for research practice". Communications of the AIS ,Vol. 4, no.7, 2000.

[33] P.Tierney, “ Work relations as a precursor to a psy chological climate for change. Journal of organizational change management, Vol. 12., no.2, pp.120-133, 1999.

[34] M.Magni, F. Pennarola, “ Intra-organizational relationships and technology acceptance". International Journal of Information Management, Vol. 28, pp. 517-523, 2008.

[35] W. Lewis, R. Agarwal, V. Sambamurthy, " Source of influence on beliefs about information technology use: An empirical study of knowledge workers, MIS Quarterly, Vol.27, no. 4, pp 657-678, 2003

[36] R.Agrawal and E. Karahanna, “ Times flies when you're having fun: cognitive absorption and beliefs about information technology usage”, MIS Quarterly, Vol. 24, no.4, pp.665- 694, 2000.

[37] V.Venkatesh, , M.G. Morris, G.B. Davis, F.Davis, "User acceptance of information technology: toward a unified view". MIS Quarterly, Vol.7, no3, pp. 425-478, 2003.

[38] L.Hossain, A. De Silva, "Exploring user acceptance of technology using social networks". Journal of high technology management research, Vol. 20, no.1, pp. 1-18, 2009.

[39] M.Anandarajan. M.Igbaria, U.P. Anakwe, ” IT acceptance in a less developed country: A motivational factor perspective", International Journal of Information Management, Vol. 22, no.1, pp. 47-65, 2002.

[40] K.E. Ghorab, “ The impact of technology acceptance considerations on system usage and adopted level of technological sophistication: An empirical investigation”, Journal of Information Management, Vol. 17, no. 4, pp. 249-259, 1997.

[41] S.Taylor , P.Todd, “ Assessing IT usage: The role of prior experience:, MIS Quarterly, Vol. 19. no.4. pp. 56-570, 1995.

[42] F. D. Davis, R. P. Bagozzi, P. R. Warshaw, "Extrinsic and Intrinsic Motivation to Use Computers in the Workplace", Journal of Applied Social Psychology, Vol. 22, no.14, pp. 1111- 1132, 1992.

[43] L. Schaper, G. Pervan . "A model of information and communication technology acceptance and utilization by occupational therapists", Decision Support in an Uncertain and Complex World: The IFIP TC8/ WG8.3 International Conference, 2004.

[44] C. May, L. Gask, T. Atkinson, N. Ellis, F.Mair, A. Esmail, " Resisting and promoting new technologies in clinical practice: the case of telepsychiatry", Social science and medicine, Vol. 52, no. 12, pp.1889-1901, 2001.

[45] P.Yellwlees, P.Brooks, "Health online: the future isn’t what it used to be" Medical journal of Australia, Vol. 171. pp.
522-525, 1999

[46] Y.S. Wang, Y.M. Wang, H.H. Lin, T.I, Tang, "Determinants of user acceptance of Internet banking: an empirical study". International Journal of Service Industry Management, Vol. 14, no.5, pp. 501-519, 2003.

[47] T.A. Horan, B. Tulu , B. Hilton,, J. Burton. “ Use of online systems in clinical medical assessment: An analysis of phy sician acceptance of online disability evaluation systems", Proceedings of the $37^{\text {th }}$ Hawaii International Conference on system sciences, 2004.

[48] V.,Venkatesh, F.D. Davis, A model of the perceived ease of use: Development and test. Decision Sciences, Vol. 27, pp. 451-481,1996.

[49] A. Sharma, "Professionals as agent: knowledge asymmetry in agency exchanges”, Academy of Management Review, Vol. 22, no. 3,pp. 758-798, 1997.

[50] V. P. Aggelidis, P.D. Chatzoglou, "Using a modified technology acceptance model in hospitals". International Journal of Medical Informatics, Vol. 78, pp.115-126, 2009.

[51] M. Lowenhaupt, "Removing barriers to technology". The Physician Executive, Vol. 30, no. 2, pp. 12-14, 2004.

[52] J. Anderson, "Increasing acceptance of clinical information systems”, MD Computing, Vol. 16, no. 1, pp. 62-5, 1999.

[53] J.G.Anderson, C.E.Aydin, “Evaluating the impact of health care information systems", International Journal of Technical Assessment in Health Care, Vol. 13, no.2, pp. 380-393,1997.

[54] M., Brennan, C. Coles, "Developing professional skills". The Lancet, 362(9394), 362-1506, 2003.

[55] C.Watts, "Erosion of healthcare professional autonomy and public respect for the profession”. Surgical Neurology, Vol. 71, no. 3, pp. 269-273,2008.

[56] J. Raelin. "An anatomy of autonomy: managing professionals", The Academy of Management Executive, Vol. 3, no. 3, pp. 216-228, 1989.

[57] A. Zuger. "Dissatisfaction with medical practice”,N Engl J Med, Vol, 350,pp. 69-75, 2004.

[58] E.N.H., Montague, B.M., Kleiner, W.W. Winchester, "Empirically understanding trust in medical technology", International Journal of Industrial Ergonomics, Vol. 39, pp. 628-634, 2009.

[59] E. Freidson, "Professional Dominance: The Social Structure of Medicine", Atherton Press, New York,1970.

[60] C. Fornell, D.F. Lacker, Evaluating structural equation models with unobserverable variables and measurement error. Journal of Marketing Research, Vol.18,no.1, pp.39-50 1981.

[61] J.M. Johnston, G.M. Leung, J.F.K. Wong, L.M. Ho, R. Fielding. Physicians' Attitudes Towards the Computerization of Clinical Practice in Hong Kong: A Population Study, International Journal of Medical Informatics, Vol. 65, pp. 41-49, 2001.

[62] I.C. Chang, H-G. Hwang, W.F. Hung, Y-C. Li, "Physicians' acceptance of pharmacokinetics-based clinical decision support systems”, Expert Systems with Applications, Vol. 33, no. 2, PP. 296-303, 2007. 
[63] M.P.Gagnon, P.,Pluye, M. Desmartis, J.Car, C. Pagliari, M.Labrecque, P. Fremont, J. Gagnon, M. Nojy a, F. Legare,. A systematic review of interventions promoting clinical information retrieval technology (CIRT) adoption by healthcare professionals,

[64] R.E. Scott, e-Records in health-preserving our future, International Journal of Medical Informatics, Vol. 76, no. 5/6, pp. 427-431,2007.

[65] N.M. Borkowski, W.R. Allen,“Does attribution theory explain physicians' non-acceptance of clinical practice guidelines?”, Hospital Topics: Research and Perspectives on Healthcare, Vol. 81, no. 2, pp. 9-21, 2003.

[66] S.Harrison, G.Dowswell, J.Wright, "Practice nurses and clinical guidelines in a changing primary care context: an empirical study”. Journal of advanced nursing, Vol.39 no.3, pp. 299-307, 2002.

[67] C.P.Yu, T.H. Chu, “Exploring knowledge contribution from an OCB perspective”, Information \& Management, Vol. 44, no. 3, pp. 321-331, 2007.

[68] A.S.Tsui, J.L.Pearce, L.W. Porter, J.P.Hite, “ Choice of employee-organization relationship: influence of external and internal organizational factors, In G.R Ferris (Ed.), Research in personnel and human resource management. Greenwich, CT:JAI press, pp. 117-151, 1995.

[69] L. Rhoades, R. Eisenberger, "Perceived organizational support: A review of the literature. Journal of Applied Psychology, Vol. 87, no.4, pp. 698-714, 2002.

[70] R.P. Settoon, R.CLiden, “ Social exchange in organizations: Perceive organizational support, Leader member exchange, and employee reciprocity. Journal of Applied Psychology, Vol. 81, no. 3, pp. 219-227, 1996.

[71] I.M. Jawahar, D. Can, "Conscientiousness and contextual performance: The compensatory effects of perceived organizational support and leader-member exchange", Journal of Managerial Psychology, Vol.22, no.4. pp.330-349, 2007.

[72] C.Viswesvaran, J.I. Sanchez, J. Fisher, “ The role of social support in the process of work stress: A meta- analysis, Journal of Vocational Behavior, Vol. 54, pp. 314-334, 1999.

[73] L.T.Eby, D.M. Adams, J.E.A Russel, S.H.Gaby, “Perceptions of organizational readiness for change: Factors related to employees' reactions to the implementation of team-based selling”. Human Relations, Vol. 53, no. 3. pp. 419-442. 2000.

[74] D.R. Self, A. Armenakis, M. Schraeder, “ Organizational change content, process and context: A simultaneous analysis of employee reactions”, Journal of change management, Vol. 7, no. 2. pp. 211-229, 2007.

[75] C.Korunka, S.Zauchner, A. Weiss, "New information technologies, job profiles, and external workload as predictors of subjectively experienced stress and dissatisfaction at work". International journal of humancomputer interaction, Vol. 9, no. 4. pp. 407-424, 1997.
[76] J.P. Meyer, N.J. Allen, ”A three component conceptualization of organizational commitment”. Human Resource Management Review, Vol. 1, pp. 61-89, 1991.

[77] G. Dowswell, S.Harrison, J. Wright, "Clinical guidelines: attitudes, information processes and culture in English primary care”, International Journal of Health Planning and Management,Vol. 16, no. 2),pp. 107-124, 2001.

[78] E.A., Bonora, O.,Revang, “A strategic framework for analyzing professional service firm _ developing strategies for sustained performance”, Strategic Management Society Inter organizational Conference, Toronto, Canada, 1991.

[79] I., Nonaka, H. Takeuchi, “The knowledge -creating company”, Oxford University Press, New York, 1995.

[80] AcNielsen, "Attitudes towards IT in Australian General Practice: Qualitative Research Report”, AcNielsen PTY General Practice Branch, North Sydney, 1998.

[81] V.Colliver, "Digital diagnosis: study could determine if online consultations will fly", San Francisco Chronicle,www.my lifep ath.com/bsc/newsroom/pub/, 2001.

[82] G., Baldwin, "Automating patient records, Technology in Practice”, www.technology inpractice.com, 2002.

[83] T.E. Becker , R.S. Billings, D.M. Eveleth, N. Gilbert, “ Foci and bases of employee commitment: implications for job performance" . Academy of Management Journal, Vol. 39. no.2, pp.464-483, 1996.

[84] K.W. Kuehn, Y. Al-Busaidi, “ Citizenship behavior in a non-western context: An examination of the role of satisfaction, commitment and job characteristics on self-reported OCB”. International Journal of Commerce and Management. Vol.2, pp.107-136. 2002.

[85] J.N. Choi, “ Multilevel and cross-level effects of workplace attitudes and group member relations on interpersonal helping behavior”. Human Performance, Vol.19,no.4, pp.383-402, 2006.

[86] L. Herscovtch, J.P. Meyer, “commitment to organizational change: Extension of a three-component model”. Journal of Applied Psychology, Vol.87. no.3, pp. 474-487. 2002.

[87] A.A. Armenakis, A.G. Bedeian, “ Organizational change: A review of theory and research in the 1990s”, Journal of Management, Vol. 25, no.3, pp.216-293, 1996.

[88] M., Conner, C. J. Armitage, "Extending the theory ofplanned behavior: A review and avenues for further research". Journal of Applied Social Psychology, Vol. 28, pp. 1429-1464, 1998.

[89] V. Venkatesh, F. Davis, “A theoretical extension of the technology acceptance model: Four longitudinal field studies”. Management Science, Vol. 46, pp.186-204, 2000.

[90] G. M. Marakas, M. Y. Yi, R. D. Johnson, “ The Multilevel and Multifaceted Character of Computer Selfefficacy: Toward Clarification of the Construct and an Integrative Framework for Research”. Information Systems Research, Vol. 9, no. 2, pp. 126-163, 1998 